\title{
The Impact of Information Technology on Real Estate Licensee Income
}

By: G. Donald Jud, Daniel T. Winkler, and G. Stacy Sirmans

Jud, G. D., D. T. Winker, and G. S. Sirmans. "The Impact of Information Technology on Real Estate Licensee Income," Journal of Real Estate Practice and Education, vol. 5, no. 1, 2002, 1-16.

Made available courtesy of American Real Estate Society:

http://www.aresnet.org/OurJournals.htm

***Note: Figures may be missing from this format of the document

\begin{abstract}
:
Executive Summary. The evolution of the Internet and other forms of information technology are changing dramatically the way the real estate brokerage industry does business. While a number of previous studies have examined the earnings of real estate salespersons, few have looked at the use of information technology as it relates to real estate licensee income. The purpose of this study is to examine this relationship using a combination of factor analysis and regression modeling. The findings support a positive impact of information technology use on the earnings of real estate licensees.
\end{abstract}

\section{Article:}

\section{Introduction}

The real estate brokerage business is on the cusp of a radical transformation brought about by cyberspace technology. The flow of information in the real estate market is increasing quickly because of the proliferation of company websites, email, cellular phones, personal digital assistants, online linkage to financing sources and other technological advances. This new information technology is transforming established institutions and opening up new venues, as many traditional brokerage activities can be delivered more quickly and with more efficiency. However, the new technology also brings forth the threat of competition from Internet-based real estate companies. Real estate licensees are in the midst of this technological revolution. This study examines how new cyberspace technology is affecting the incomes of real estate licensees, using a factor analytic approach to capture the multifaceted effects of technological change.

The analysis of real estate licensee earnings is grounded in the human capital theory developed by Mincer (1970), Becker (1975) and others. Labor economists using this approach have studied the returns to schooling, training and experience. A number of previous studies have examined the factors that determine the income for real estate salespersons. Research by Follain, Lutes and Meier (1987), Crellin, Frew and Jud (1988) and Glower and Hendershott (1988) were among the early studies of real estate licensee income using survey data from individual agents. Sirmans and Swicegood (1997) extend the analysis to include psychological and managerial measures such as job satisfaction and perceived negative image of the industry. Sirmans and Swicegood (2000) later examined how licensee income is impacted by other productivity influences such as technology and the use of assistants. Crellin, Frew and Jud, drawing on a nationwide sample, found a significant metropolitan income effect. Similarly, Jud and Winkler (1998) found a 
geographic influence in their study of income of professionals in real estate, securities and insurance sales. 1

Few studies have examined the impact of new information technology on the earnings of brokers. The only recent study that deals with this topic is by Sirmans and Swicegood (2000) who report that high-income agents use computers no more intensively than low-income agents. The following sections discuss how technological change can affect the earnings of residential real estate brokers and salespersons. The next section provides an overview of the impact of recent technological changes on the incomes of real estate licensees. The sections that follow set forth the analytical model, and discuss the data and empirical results. The final section provides an overall summary and an evaluation of findings.

\section{The Internet and the Earnings of Brokers}

New cyberspace technology is making the housing search process cheaper and easier (Tessler, 1999). Real estate websites such as NAR's Realtor.com and Microsoft's Home-Advisor.com allow potential buyers to search available properties by location or zip code and narrow the search by adding information on desired amenities and price range. Many sites also provide virtual tours of home interiors, allowing buyers a 360 deg view of each room. When web searchers find something that meets their specifications, they can email their interest to the seller or the listing broker.

Websites also provide basic information about the home-buying process, loan qualification and other basics of a real estate transaction. They offer information about communities such as tax rates, school test scores, crime rates, etc. They also provide links to service providers: mortgage bankers, moving companies, utility providers, etc. Tools such as mortgage loan calculators and links to online appraisal services are commonly provided.

These online services are provided free to consumers because online service providers generate revenue by selling advertisements and links to other websites. This creates competition among sites to offer the most services to capture the highest traffic volume. Real estate websites can represent substantial resource commitments by their sponsors and there is continued pressure to expand and consolidate to capture an everlarger market share. This dynamic creates substantial change in the brokerage industry and the way services are provided.

Traditionally, brokerage firms have worked together to increase the efficiency of housing search through the local multiple listing service (MLS). By cooperating and sharing information through their MLS, brokers reduced the cost and raised the efficiency of search. Because access to the MLS was available to market participants only through member brokers, the MLS gave members an informational monopoly. Now, however, with the potential availability of free market information online, the power of the MLS monopoly may be endangered.

The National Association of Realtors (NAR) has sought to protect their member's special position in the housing market by its investment in and promotion of Homestore.com Inc., an online real estate company. NAR and many local boards own a substantial interest in Homestore.com (Barta, 2000). Realtors have attempted to preserve their monopoly position through proprietary agreements to share access to the hundreds of thousands of home listings in 
local multiple listing services only with Homestore.com. Listings on the Homestore.com website withhold the phone numbers of sellers, forcing potential buyers to contact a realtor.

While the U.S. Department of Justice is reported to be looking into the antitrust implications of NAR's relationship with Homestore.com (Guidera, 2000), NAR has launched a new initiative through its investment in e-Realtor.com. This new online platform would allow buyers, sellers and others involved in a housing market transaction to exchange documents online (Barta, 2000). The service would be offered to buyers and sellers who use a realtor in their housing search. Others who use or advertise on the site will be charged to participate.

Whatever the result of the NAR's initiatives to preserve the monopoly position of realtors, the Internet will continue to make real estate markets more efficient because it increases the quality and quantity of information available to buyers and sellers. Traditional real estate brokerage companies have more competition, perhaps even eventually driving the unbundling of service costs. In short, consumers are the winners by being able to make better-informed decisions at lower costs. From an industry perspective, however, the demand for brokerage services is a function of the cost of search and declining search costs reduce the demand for brokerage services. Because the Internet makes a real estate market search easier and provides more information at a lower cost, it may reduce the demand for real estate brokerage services. A recent report by Banc of America Securities predicts that real estate brokerage commissions, which at present total some $\$ 18.8$ billion annually, will fall $11 \%$ over the next three years (Rich, 2000).

A study by the National Association of Realtors (NAR, 2000) conducted in 1999 suggests that the Internet has not yet had a detrimental impact on the business of realtors. Only $4 \%$ of homebuyers first learned about the home that they ultimately purchased from the Internet. However, $37 \%$ of homebuyers report using the Internet as an information source during their home search. Almost half of the homebuyers in 1999 first learned about the home they purchased from a real estate agent; this is almost unchanged from ten years earlier. Interestingly, $87 \%$ of homebuyers who use the Internet used a real estate agent or broker to complete the search and transaction compared to only $76 \%$ of others. The results of the NAR survey suggest that homebuyers may use the Internet as a secondary information source. The Internet appears to provide potential buyers with timely information and may reduce search time and the time spent by brokers and agents to provide such service.

Adoption of the new information technology puts the greatest strain on the older, less technology-proficient members of the profession. However, all brokerage professionals are being forced to make ever-larger investments of human and physical capital to be competitive. The declining demand for services and increasing need for investment expenditures could result in substantial market consolidation. Those individuals and firms that remain will survive by using information technology to raise their operating efficiency to levels that are competitive.

Brokers and brokerage firms will employ more information technology in their business because of competitive pressures and the falling price of information technology. In the competitive real estate sales industry, brokers and salespersons should expect to receive the value of their marginal product $\left(\mathrm{MP}^{\wedge} \mathrm{sub} \mathrm{L}^{\wedge}\right)$, that is, Wage $=\mathrm{P}^{*} \mathrm{MP}^{\wedge}$ sub $\mathrm{L}^{\wedge}$, where $\mathrm{P}=$ the price of brokerage services. As a factor in the production of brokerage services, information technology 
affects the broker's marginal product and, therefore, income as well. Accordingly, brokers who are more proficient with the new information technology and use it more extensively should earn higher incomes than others who do not.

\section{Analytical Model}

Although the full effects of the current technological revolution have not been fully realized and may take years to fully interpret, this study provides some initial evidence on the impact of information technology on real estate licensee income.

To examine the impact of information technology usage on licensee earnings, the standard human capital earnings model developed by Mincer (1970) is used. Benjamin, Jud and Sirmans (2000) review the factors that have been found to exert an effect on licensee income. The positive effects on licensee income include: (1) number of hours worked; (2) experience; (3) schooling; (4) firm size; (5) manager/ ownership interest; (6) firm reputation; (7) franchise affiliation; (8) working in a metro area; and (9) professional designations. 2 Factors that have been found to negatively affect licensee income are: (1) selling residential property; (2) holding a sales license as opposed to being a broker; (3) having a perceived negative image of the industry; and (4) being female. 3

The general form of the model estimated here is:

Linc $=\mathrm{f}($ Lhrs, Sch, Exp, Exp2, Expf, Brok, Fran, Buyb, Techf $),(1)$

where:

Linc $=$ The natural log of annual earnings;

Lhrs = The natural log of the number of hours worked;

Sch $=$ The number of years of schooling;

$\operatorname{Exp}=$ The number of years of real estate market experience;

Exp2 $=$ The number of years of real estate market experience squared;

Expf $=$ The number of years of experience with the specific firm;

Brok = A dummy variable indicating a broker's license;

Fran $=$ A dummy variable indicating a national franchise affiliation;

$\mathrm{Buyb}=$ The percentage of income from buyer brokerage; and

Techf $=$ A variable measuring the licensee's use of information technology.

Human capital theory suggests that the schooling and experience variables should have a positive effect on licensee income. The Exp2 variable captures the nonlinear influence of experience on earnings, as the benefits of experience are expected to increase but at a decreasing rate. Jud and Winkler (1998) find that the maximum benefit of experience occurs with 28-29 years of experience; Glower and Hendershott (1988) estimate the maximum point is reached at 15-20 years. Several studies reviewed by Benjamin, Jud and Sirmans (2000) found that brokers earn more than salespersons, as do licensees who are affiliated with a national franchise. They also report that buyer brokers have been found to earn less than traditional brokers representing the seller. Potential explanations for the lower earnings of buyer brokers might be that buyer broker relationships with customers are more time intensive or that the negotiated commissions are less. Sirmans and Swicegood (1997) find the buyer broker variable to be statistically insignificant. 
The information technology variable (Tech is created by combining multiple variables in a factor analysis. The factor analysis has two distinct advantages. First, including many similar technology variables in a regression is likely to result in substantial collinearity, making interpretation of the coefficients difficult. A second benefit is the informational advantage of isolating the similar technology effect while reducing the noise associated with the disparate variables. Sirmans and Swicegood (2000) attempt to identify a technology effect with direct inclusion of the technology variables in a regression, but only one (use of computers) of seven variables is statistically significant at the $10 \%$ level. The use of factor analysis is designed to more effectively isolate the impact of technology on licensee income.

The variables combined for the factor analysis include the following: (1) Web, whether a firm has a web page; (2) Webp, whether the respondent has a personal website; (3) Weblist, whether the firm has web listings of properties; (4) Internet, hours of use per week of the Internet; (5) Email, percentage of clients contact using email; (6) Tech, number of different technologies used (for example, internet website, email address, digital camera, Palm pilot, etc.); (7) Soft, the number of software applications used; and (8) Cage, the age of the licensee's computer.4

\section{Data and Empirical Results}

\section{Data Description}

The data for this study are obtained from a survey of real estate licensees conducted by the authors for the Greensboro Regional Realtors Association. Greensboro is a medium-sized city in central North Carolina. It is the principal city in Guilford County, which had a total population of 421,048 in 2000. A survey of 983 real estate professionals was conducted during the summer of 2000. The survey questionnaire is shown in Appendix 1. The response rate was 29.7\%, or 292 completed surveys. Of these, 276 were responses from brokers and salespersons. Missing, and incomplete, responses for the variables in this study resulted in a final sample of 149 observations.

The survey instrument, shown in Appendix 1, is divided into five parts as follows: (1) personal information; (2) real estate related activities; (3) professional designations; (4) firm characteristics; and (5) technology use.5

Summary statistics for the variables used in the regression analysis are shown in Exhibit 1. Approximately $64 \%$ of respondents have a broker's license, and thirtyseven are associated with a national franchise firm. The average workweek is 46.8 hours. The mean annual earnings of those in the sample is $\$ 63,449$. Respondents have an average of 15.3 years of schooling. The average experience of respondents is almost 13.7 years and they have been with their current firm an average of 7.0 years. Sample respondents receive an average of $41 \%$ their income from buyer brokerage.

\section{Factor Analysis}

The factor analysis results indicate that the information technology variables have three common factors with eigenvalues exceeding 1.0, with a cumulative explained variation of $61.91 \%$. The factor analysis results for the first factor, with the largest eigenvalue and explained proportion of the variance, are shown in Exhibit 2.6 
The first factor has an explained proportion of variance of 0.309 with an eigenvalue of 2.47. The results indicate that the existence of a firm website, a personal website and real estate listings on the web are positively related to the primary information technology factor. Likewise, a positive association occurs between more extensive use of the Internet, email, various technologies, and software applications and the primary information technology factor. As expected, computer age is negatively related to the primary information technology factor.

\section{Exhibit 1}

Summary Statistics

\begin{tabular}{lrr}
\hline Variable & \multicolumn{1}{c}{ Mean } & Std. Dev. \\
\hline Lhrs & 3.80 & 0.365 \\
Hrs & 46.82 & 10.843 \\
Sch & 15.28 & 1.395 \\
Exp & 13.73 & 8.653 \\
Exp2 & 263.12 & 275.958 \\
Expf & 7.04 & 6.121 \\
Brok & 0.64 & 0.482 \\
Fran & 0.37 & 0.484 \\
Buyb & 41.46 & 30.562 \\
Techf & -0.02 & 1.002 \\
Linc & 10.91 & 0.552 \\
Inc & $\$ 63.449 .00$ & $\$ 33,580.00$ \\
\hline
\end{tabular}

\footnotetext{
Notes: $n=149$.

Lhrs $=$ Natural log of the number of hours worked

Hrs $=$ Number of hours worked

Sch $=$ Number of years of schooling

Exp $=$ Number of years of real estate market experience

Exp2 $=$ Number of years of real estate market experience squared

Expf $=$ Number of years of experience with the specific firm

Brok $=$ Dummy variable indicating a broker's license

Fran $=$ Dummy variable indicating a national franchise affiliation

$B u y b=$ Percentage of income from buyer brokerage

Techf $=$ Variable measuring the licensee's use of information technology

Linc $=$ Natural log of annual earnings

Inc $=$ Annual earnings
}

The mean of the primary information technology factor is -0.02 with a standard deviation of 1.002, as shown in Exhibit 1.7 Exhibit 3 illustrates the distribution of the primary information technology factor. Exhibit 3 shows that the information technology factor is essentially normally distributed; more than half of the values are in the range $-1<\operatorname{Techf}<1$.

\section{Regression Analysis}


The regression results are reported in Exhibit 4. The correlation matrix for all variables in the analysis is shown in Appendix 2. The regression model adjusted $\mathrm{R}^{\wedge} \mathrm{sub} 2^{\wedge}$ is approximately $45 \%$; the model is statistically significant at the 0.01 level.

The regression variables are all statistically significant at the 0.10 level with the exception of the franchise variable (Fran). The Lhrs variable indicates that net earnings of salespersons increase about $0.4 \%$ for every $1 \%$ in hours worked, suggesting diminishing returns to additional hours worked. Sirmans and Swicegood (2000) report a similar income elasticity coefficient for hours worked of 0.22 .8 The estimated return per year of schooling is about $4.2 \%$. Similarly, an additional year of experience increases earnings about $4.4 \%$ per year; however, the increase is at a decreasing rate, as indicated by the negative coefficient on the Exp2 variable. The earningsexperience function reaches a maximum at 22 years. Real estate brokers earn about $28 \%$ more than salespersons.9 Buyer brokers earn less than traditional seller brokers. In Exhibit 3, the coefficient on Buyb suggests that earnings fall $0.3 \%$ for every $1 \%$ increase in the percentage of total earnings that is received from buyer brokerage.

The information technology factor (Techf) is statistically significant at the $5 \%$ level, and as expected, shows the expected positive relationship with net earnings. The estimated coefficient indicates that a one standard deviation change in technology usage is associated with a $9.6 \%$ increase in earnings. 10

\section{Conclusion}

The cyberspace revolution places a premium on proficiency in the use of information technology tools to maintain and increase worker productivity. This article has explored the impact of information technology on the earnings of real estate licensees. Analysis shows that, on average, licensees who increase their use of information technology by one standard deviation unit more than others, increase their earnings by $9.6 \%$. Referring to the mean and standard deviation of Techf, shown as -0.02 and 1.002 in Exhibit 1 respectively, and the distribution of this variable as shown in Exhibit 3, a one standard deviation change would be the top $15 \%$ to $20 \%$ in the Techf distribution.11 These results suggest that the use of information technology offers the potential for substantial income gains.

Among the other determinants of earnings found to be important are: schooling, experience (both general and firm-specific), hours worked and having a broker's license. Affiliation with a national franchise is not significant, while working as a buyer's broker has a significant, but negative effect on earnings. 
Exhibit 2

Factor Analysis

\begin{tabular}{lclc}
\hline Technology Variable & Factor Loading & Factor Variance & Scoring Coefficient \\
\hline Web & 0.653 & 0.862 & 0.264 \\
Webp & 0.513 & 0.410 & 0.207 \\
Weblist & 0.647 & 0.856 & 0.262 \\
Internet & 0.436 & 0.380 & 0.176 \\
Email & 0.441 & 0.514 & 0.178 \\
Tech & 0.700 & 0.604 & 0.283 \\
Soft & 0.629 & 0.650 & 0.254 \\
Cage & -0.305 & 0.677 & -0.123 \\
\hline
\end{tabular}

Notes: $n=185$; Eigenvalue $=2.472$; and Proportion of Variance $=0.309$.

$W e b=$ Whether a firm has a web page

Webp $=$ Whether the respondent has a personal website

Weblist $=$ Whether the firm has web listings of properties

Internet $=$ Hours of use per week of the Internet

Email $=$ Percentage of client contact using email

Tech $=$ Number of different technologies

Soft $=$ The number of software applications used

Cage $=$ The age of the licensee's computer

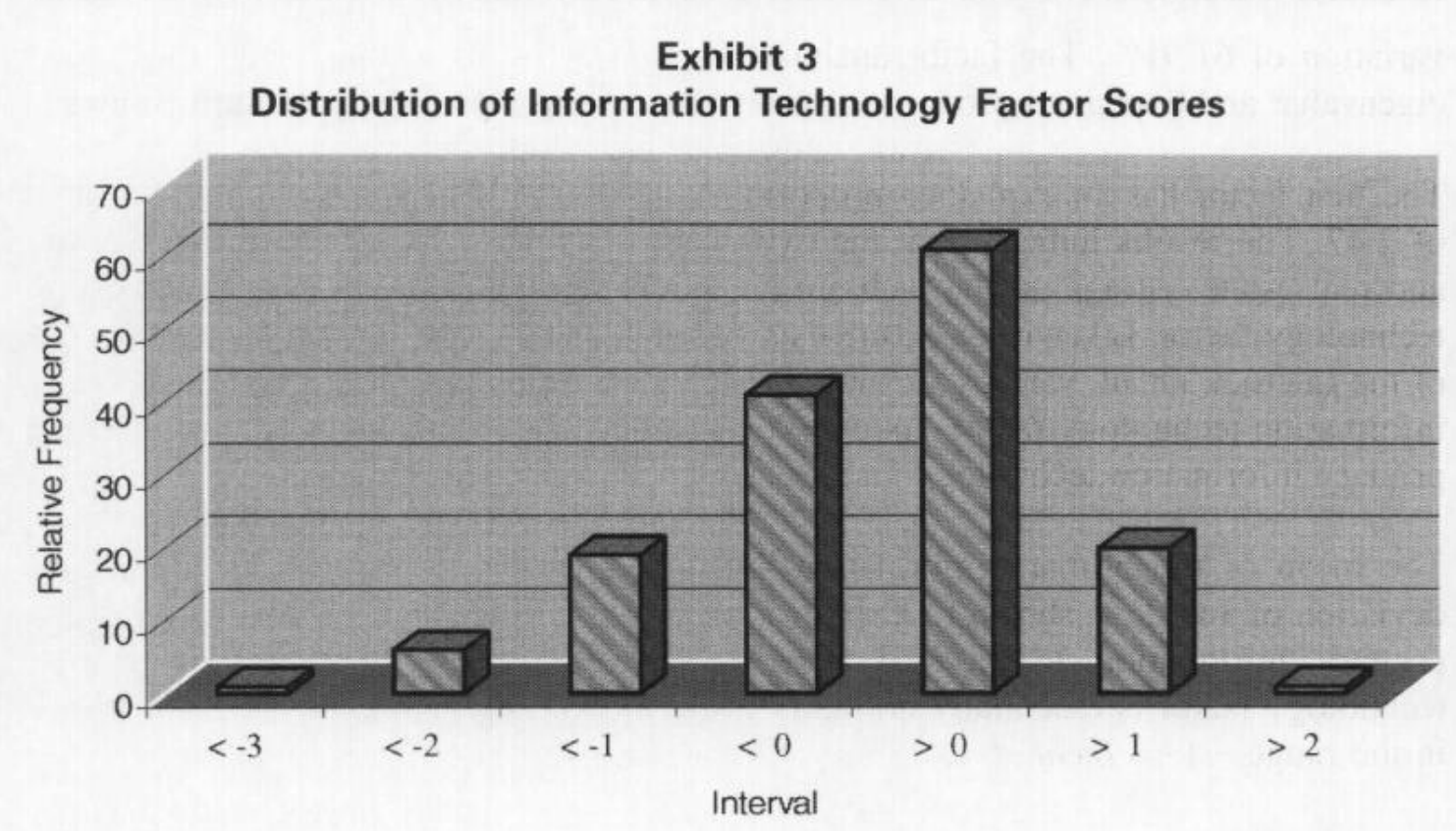




\section{Exhibit 4}

Regression Analysis of Salesperson Income

\begin{tabular}{lrlr}
\hline Variable & Estimate & Standard Error & T-Value \\
\hline Intercept & 8.210 & 0.580 & $14.16^{*}$ \\
Lhrs & 0.397 & 0.100 & $3.97^{*}$ \\
Sch & 0.042 & 0.025 & $1.67^{*}$ \\
Exp & 0.044 & 0.015 & $2.87^{*}$ \\
Exp2 & -0.001 & 0.000 & $-2.50^{*}$ \\
Expf & 0.029 & 0.007 & $3.91^{*}$ \\
Brok & 0.247 & 0.082 & $3.00^{*}$ \\
Fran & 0.120 & 0.075 & 1.60 \\
Buyb & -0.003 & 0.001 & $-2.78^{*}$ \\
Techf & 0.095 & 0.040 & $2.37^{*}$ \\
\hline
\end{tabular}

Notes: Adjusted $R^{2}=.45 ;$ Model F-Value $=14.37 ;$ and $\mathrm{N}=149$.

Lhrs $=$ Natural log of the number of hours worked

Sch $=$ Number of years of schooling

$\operatorname{Exp}=$ Number of years of real estate market experience

Exp2 = Number of years of real estate market experience squared

Expf $=$ Number of years of experience with the specific firm

Brok $=$ Dummy variable indicating a broker's license

Fran $=$ Dummy variable indicating a national franchise affiliation

Buyb $=$ Percentage of income from buyer brokerage

Techf = Variable measuring the licensee's use of information technology

${ }^{*}$ Indicates significance at the .10 level. 


\section{Appendix 1}

\section{Greensboro Regional Realtor Association Survey}

Please circle the letter of the appropriate answer or write in your response when necessary.

\section{Personal Information}

1. What is your age?
A. Less than 25
D. $35-39$
G. $50-54$
J. $65-70$
B. $25-29$
E. $40-44$
H. $55-59$
C. $30-34$
F. $45-49$
K. $71 \&$ over
I. $60-64$

2. What is your gender?

A. Male

B. Female

3. What is your race/ethnicity?
A. Asian
D. African-American
B. Hispanic
E. Other
C. Caucasian

4. What is the highest level of education you have attained?
A. Did not complete high school
D. Bachelor's Degree
B. High school diploma
C. Some college
E. Master's Degree
F. Doctoral Degree

5. If you have been in college, what was your major?
A. Business, economics
C. Liberal arts
B. Engineering, math, science
D. Other

6. Which of the following licenses do you hold?
A. Real Estate Broker
C. Appraiser
E. Auctioneer
B. Real Estate Salesperson
D. Insurance
F. Mortgage Broker

7. Do you hold a real estate license from a state other than North Carolina?
A. Yes
B. No
If yes, from what other state(s)?

8. How many hours per month do you spend reading industry-related literature?
A. 1-2
C. 5-9
E. None
B. $3-4$
D. 10 or more

9. What are your primary sources of industry-related information? (Circle all that apply.)
A. TV
D. Internet
B. Periodicals
E. Trade publications
C. Conferences/Seminars
F. Radio
G. Newspapers
H. Audio tapes
I. Video tapes

\section{Real Estate Related Activities}

10. Approximately how many years have you been actively engaged in the real estate business (in any capacity)?
A. 2 or less
D. 9-11
G. $18-20$
J. 27 or more
B. $3-5$
E. $12-14$
H. 21-23
C. $6-8$
F. $15-17$
I. 24-26 
11. Approximately how many years have you been a member of the Greensboro Regional Realtors Assn. (GRRA)?
A. Not a member
D. $6-8$
G. $15-17$
J. $24-26$
B. 2 or less
E. $9-11$
H. $18-20$
K. 27 or more
C. $3-5$
F. $12-14$
I. $21-23$

12. Approximately how many hours per week, on average, do you work in real estate activities?
A. 6 or less
D. $21-27$
G. $40-44$
J. 57 or more
B. $7-13$
E. $28-34$
H. $45-49$
C. $14-20$
F. $35-39$
I. $50-56$

13. Including your current affiliation, how many real estate firms have you been affiliated with in your real estate career?
A. One
C. Three
E. Five or more
B. Two
D. Four

14. How long have you worked with your current firm?
A. 1 year or less
C. $4-5$ years
E. $10-19$ years
B. 2-3 years
D. $6-9$ years
F. 20 years or more

15. If you sell/lease real estate, how many personal assistants do you use?
A. None
C. Two
E. Four
B. One
D. Three
F. Five or more

16. If you sell/lease real estate, what do you use the personal assistants for? (Circle all that apply.)
A. Gathering data
D. Clerical
G. Other
B. Interviewing clients
E. Preparing documents
C. Showing homes
F. Arranging inspections
H. Not applicable

In answering Questions $17 \& 18$, please refer to the following list of activities in which real estate professionals engage:
A. New single-family sales
F. Exchanges
K. Counseling
B. Existing single-family
G. Investment sales
H. Teaching \& training
L. Building \&
I. Property management development
C. Commercial sales/leasing
J. Appraising
M. Mortgage finance
D. Industrial sales/leasing
E. Farm and land sales
N. Home inspection
O. Other

17. In which one of these activities do you devote most of your time?

(A thru O)

18. In which other activities do you devote a significant percentage of your time?

Activity (A thru O)

Activity (A thru O)

Activity (A thru O)

Activity (A thru O)
Percentage of time

Percentage of time

Percentage of time

Percentage of time $\%$ $\%$ $\%$ 
19. What was your approximate gross personal income from real estate brokerage activities (not net of business expenses) for the year 1999?
A. $\$ 9,999$ or less
E. $\$ 40,000$ to $\$ 49,999$
I. $\$ 80,000$ to $\$ 89,999$
B. $\$ 10,000$ to $\$ 19,999$
F. $\$ 50,000$ to $\$ 59,999$
J. $\$ 90,000$ to $\$ 99,999$
C. $\$ 20,000$ to $\$ 29,999$
G. $\$ 60,000$ to $\$ 69,999$
K. $\$ 100,000$ to $\$ 124,999$
D. $\$ 30,000$ to $\$ 39,999$
H. $\$ 70,000$ to $\$ 79,999$
L. $\$ 125,000$ or more

20. Approximately what percentage of your gross income from real estate for 1999 was used to paybusiness expenses?
A. $4 \%$ or less
D. $20 \%-29 \%$ G. $50 \%$ or more
B. $5 \%-9 \%$
E. $30 \%-39 \%$
C. $10 \%-19 \%$
F. $40 \%-49 \%$

21. In 1999, approximately, how many real estate transactions (sales) were you involved in?
A. None
D. $10-14$
G. 25-29
J. 40-44
B. 1-4
E. $15-19$
H. $30-34$
K. 45-49
C. 5-9
F. 20-24
I. $35-39$
L. 50 or more

22. Approximately what percentage of your transactions in 1999 did you receive a commission as
A. Listing agent only
C. Both
B. Selling agent only

23. In approximately what percentage of your transactions in 1999 did you represent the:
A. Seller
C. Both
B. Buyer

24. If you are a salesperson, what is your commission split with the broker/firm?
A. $90 \%-100 \%$
C. $70 \%-79 \%$
E. $50 \%-59 \%$
G. $30 \%-39 \%$
B. $80 \%-89 \%$
D. $60 \%-69 \%$
F. $40 \%-49 \%$
H. $29 \%$ or less

Professional Designations (for Questions 25-26)
A. GRI
E. AFLM
I. LTG
M. SIOR
B. CPM
F. CRE
J. MAI
N. CPM
C. CRS
G. CRM
K. RM
O. SRA
D. CCIM
H. CRB
L. SRS
P. Other

25. Which of the above designations do you hold? (A thru. P)

26. Which of the above designations are you a candidate for or actively working toward? (List all that apply.)

(A thru. P)

27. If you have or are working toward a designation, is it primarily because the designation you most eagerly seek will increase your (circle one).
A. Professional prestige
C. Income because of greater contacts
B. Income because of better knowledge
D. Ability to perform your job better 


\section{Firm Characteristics}

28. Which single statement best describes your function in your firm?
A. Management-non-selling
B. Management-selling
E. Major owner ( $25 \%$ or more of firm) -
C. Broker in charge
D. Salesperson non-selling
F. Major owner ( $25 \%$ or more of firm) - selling
G. Property manager
H. Other

29. About how many licensees are actively affiliated with your local firm?

30 . Is your firm affiliated with a ? (Circle all that apply.)
A. National franchise company
D. Independent (local) franchise company
B. National referral/network
E. Relocation/management company
C. National company
F. Not affiliated at all (independent)

31. What is the zip code in which your office is located?

32. Does your firm have its own web site? (please circle) YES NO

33. If your firm has a website, can your clients view your firm's listings on it? (Please circle) YES NO

34. List the three most important marketing tools employed by your firm (for example, newspaper advertising, sponsoring open houses, the internet, etc.).
A.
B.
C.

\section{Technology Use}

35. Please circle all of the technologies that you use?
A. Personal computer
E. Laptop computer
I. Cellular phone
B. Modem
F. Digital camera
J. Video camera
C. Internet website
G. Color printer
K. Fax machine
D. Email address
H. Scanner
L. Palm pilot

36. About how old is the personal computer you use most often?
A. Less than 6 mos.
C. 1 to 2 years
B. 6 mos. to 1 year
D. More than 2 years

37. Which of the following software applications do you use? (Circle all that apply.)
A. Word processor
E. Presentation graphics
I. Internet
B. Spreadsheet
F. Financial management
J. Financial analysis
C. Database
G. Contact management
K. MLS
D. Property management
H. Virtual tours
L. None

38. Please list up to three of the most important real estate software programs that you use.
A.
B.
C. 
39. What percentage of your contact with clients do you do using email? $\%$

40. How many hours per week do you use the Internet?

Hours.

41. What technology education programs would you like to see offered by GRRA? (Circle all that apply.)
A. Word processor
E. Presentation graphics
I. Internet
B. Spreadsheet
F. Financial management
J. Financial analysis
C. Database
G. Contact management
K. MLS
D. Property management
H. Virtual tours
L. None

42. In what other real estate organizations do you actively participate? (Circle all that apply)
A. IREM
E. NNA
I. BOMA
B. NAIOP
F. Appraisal Institute
J. WCR
C. CCIM
G. TREBIC
K. Other
D. NACORE
H. SCORI

43. Do you have a personal web site(s)?
A. Yes
B. No
If yes, how many?

44. What impact do you believe the internet will have on careers in your field over the next five years?
A. Significant positive impact
B. Moderate positive impact
C. Neither positive nor negative impact
D. Moderate negative impact
E. Significant negative impact

\section{Appendix 2}

\section{Correlation Matrix}

\begin{tabular}{lrrrrrrrrrr}
\hline Variable & \multicolumn{1}{c}{ Lhrs } & \multicolumn{1}{c}{ Sch } & Exp & Exp2 & Expf & Brok & Fran & Buyb & Techf & Linc \\
\hline Lhrs & 1.000 & 0.046 & 0.018 & 0.029 & -0.036 & 0.053 & 0.028 & -0.163 & 0.302 & 0.349 \\
Sch & 0.046 & 1.000 & -0.049 & -0.039 & 0.015 & -0.068 & -0.065 & -0.084 & 0.189 & 0.138 \\
Exp & 0.018 & -0.049 & 1.000 & 0.964 & 0.638 & 0.494 & -0.288 & -0.321 & -0.359 & 0.390 \\
Exp2 & 0.029 & -0.039 & 0.964 & 1.000 & 0.644 & 0.455 & -0.285 & -0.296 & -0.397 & 0.330 \\
Expf & -0.036 & 0.015 & 0.638 & 0.644 & 1.000 & 0.368 & -0.244 & -0.263 & -0.288 & 0.418 \\
Brok & 0.053 & -0.068 & 0.494 & 0.455 & 0.368 & 1.000 & -0.262 & -0.133 & -0.148 & 0.380 \\
Fran & 0.028 & -0.065 & -0.288 & -0.285 & -0.244 & -0.262 & 1.000 & 0.168 & 0.193 & -0.055 \\
Buyb & -0.163 & -0.084 & -0.321 & -0.296 & -0.263 & -0.133 & 0.168 & 1.000 & 0.041 & -0.369 \\
Techf & 0.302 & 0.189 & -0.359 & -0.397 & -0.288 & -0.148 & 0.193 & 0.041 & 1.000 & 0.151 \\
Linc & 0.349 & 0.138 & 0.390 & 0.330 & 0.418 & 0.380 & -0.055 & -0.369 & 0.151 & 1.000 \\
\hline
\end{tabular}




\section{Endnotes}

1. Benjamin, Jud and Sirmans (2000) summarize and review this research.

2. To properly specify the model, it is necessary to include both experience (Exp) and experience squared (Exp2). Studies by Glower and Hendershott (1988), Jud and Winkler (1998) and Sirmans and Swicegood $(1997,2000)$ have found that the returns to experience increase at a decreasing rate; these studies include both Exp and Exp2 in their models. Sirmans and Swicegood (1997, 2000) also test experience measured by years with the current firm (Expf), and therefore, this measure of experience is included here as well.

3. Similar to Follain, Lutes and Meier (1987), gender is not statistically significant in the model; therefore, it is not included in the regression.

4. These variables correspond with the following questions shown in the survey instrument (Appendix 1): Web = Q32, Webp = Q43, Weblist $=$ Q33, Internet $=$ Q40, Email $=$ Q39, Tech $=$ $\mathrm{Q} 35$, Soft $=\mathrm{Q} 37$ and Cage $=\mathrm{Q} 36$.

5. An itemized listing of the survey responses to each question on the survey questionnaire is available from the authors.

6. The second factor has an eigenvalue of 1.46 and an explained variation of $18.21 \%$, while the third factor has an eigenvalue of 1.02 and an explained variation of $12.80 \%$. Unfortunately, the pattern relating the eight technology variables has no logical explanation, and neither of these factors was statistically significant in the regression analysis.

7. The mean of the primary information is -.018 rather than 0.0 because the factor analysis was conducted using 185 observations (all of the survey respondents that answered the information technology questions). The regression analysis was conducted using only 149 survey respondents, because of other missing or incomplete data. When calculated over the smaller sample, the mean of the information technology factor is -0.018 .

8. This income elasticity coefficient can vary considerably; Sirmans and Swicegood report this coefficient to be 0.910 in their 1997 study. As a comparison, Crellin, Frew and Jud (1988) report this coefficient as 0.634 for a national sample.

9. The possibility that the broker variable was capturing variation attributable to being the majority owner of a firm (see question \#28 in Appendix 1) was also tested. However, a variable for majority ownership was not statistically significant in the regression equation. The estimated percentage change for the Brok variable as reported in Exhibit 4 can be determined by the following transformation: $\exp (\mathrm{D})-1$, where $\mathrm{D}$ is the dummy variable coefficient.

10. When the relationship between technology use and the other independent variables in the model was examined, the use of information technology (Techf) was found to be significantly related to hours-worked, schooling and franchise affiliation. Interestingly, there was no significant association with age, gender, race, buyer-brokerage or possession of a brokerage license.

11. A similar analysis using the mean and standard deviation could be conducted for the other independent variables; this approach is reasonable when the units of measurement do not inherently offer an intuitive explanation. Other variables such as years of schooling and experience do not have the same interpretation problems.

\section{References}

Barta, P., Realtors Invest in Job Security on the Internet, The Wall Street Journal, (Monday) November 6, 2000, B 1. 
Becker, G. S., Human Capital, Second edition, New York, NY: Columbia University Press, 1975.

Benjamin, J. D., G. D. Jud and G. S. Sirmans, What Do We Know About Real Estate Brokerage?, Journal of Real Estate Research, 2000, 20:1/2, 5-30.

Crellin, G. E., J. R. Frew and G. D. Jud, The Earnings of REALTORS: Some Empirical Evidence, Journal of Real Estate Research, 1988, 3:2, 69-78.

Follain, J. R., T. Lutes and D. S. Meier, Why Do Some Real Estate Salespeople Earn More Than Others?, Journal of Real Estate Research, 1987, 2:3, 73-81.

Glower, M. and P. H. Hendershott, The Determinants of REALTOR Income, Journal of Real Estate Research, 1988, 3:2, 53-68.

Guidera, J., Antitrust Investigation of Homestore.com is Focusing on Exclusive Listing Pacts, The Wall Street Journal, September 20, 2000, C22.

Jud, D. G. and D. T. Winkler, The Earnings of Real Estate Salesperson and Others in the Financial Services Industry, Journal of Real Estate Finance and Economics, 1998, 17:3, 27991. Mincer, J., The Distribution of Labor Incomes: A Survey with Special Reference to the Human Capital Approach, Journal of Economic Literature, 1970, 8:1, 1-26.

National Association of Realtors,, The 2000 National Association of Realtors Profile of Home Buyers and Sellers, Kevin A. Roth, principal author, 2000.

Rich, M., For Brokers, the Internet Looms Ever Larger, The Wall Street Journal, (Wednesday) August 23, 2000, B12.

Sirmans, G. S. and P. G. Swicegood, Determinants of Real Estate Licensee Income, Journal of Real Estate Research, 1997, 14:1/2, 137-59.

., Determining Real Estate Licensee Income, Journal of Real Estate Research, 2000, 20:1/ 2, 189204.

Tessler, J., More People Turn to Web to Buy, Sell Homes, The Wall Street Journal, (Thursday) July 8, 1999, B9. 